\title{
Electronic Bond Structure of Carbon Nitride Thin Film Deposited by HiPIMS and dc Magnetron Plasma
}

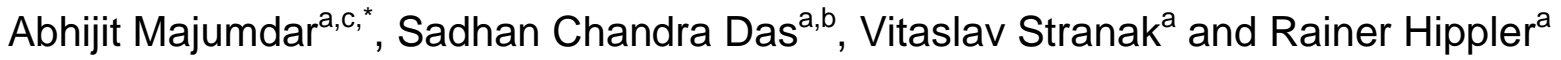 \\ ${ }^{a}$ Institute of Physics, University of Greifswald, Felix-Hausdorff-Str. 6, 17489 Greifswald, Germany \\ ${ }^{b}$ UGC-DAE Consortium for Scientific Research, Indore 452017, MP, India \\ ${ }^{c}$ Department of Physics, Indian Institute of Engineering Science and Technology, Shibpur, Howrah-3, West Bengal, India
}

\begin{abstract}
We report the difference in electronic bond structure and surface chemical property of amorphous carbon nitride $\left(\mathrm{a}-\mathrm{CN}_{\mathrm{x}}\right)$ film as a function of $\mathrm{N} / \mathrm{C}$ which has been deposited by high power impulse magnetron sputtering (HiPIMS) and DC magnetron (dc-MS) plasma. The spectroscopic analyses suggest that the presence of oxide layer is the major cause for the surface charging in the core level peak. The core electron peaks (C1s, N1s and O1s) in x-ray photoelectron spectroscopy (XPS) show higher surface charging in HiPIMS compare to the film deposited by dc-MS plasma. The core peaks are moved gradually toward its virgin position as the etching duration is increased from $1 \mathrm{~min}$ to 80 mins. The films deposited by HiPIMS retain a higher N/C ratio following ion etching as compared to those deposited by DC magnetron sputtering suggesting denser films with a higher degree of cross-linking.
\end{abstract}

Received on 15-10-2014 Accepted on 09-02-2015 Published on 24-04-2015 Keywords: Carbon nitride, HiPIMS, dc-MS, a-CNx disintegration by Ar-sputter clean, Surface charging, $\mathrm{X}$ ray photoelectron spectroscopy.

\section{INTRODUCTION}

Amorphous carbon nitride $\left(\mathrm{a}-\mathrm{CN}_{\mathrm{x}}\right)$ films are expected to be applicable widely as, for example, super hard coating material with low friction coefficient [1, 2], low band gap protective material on hard disks and read heads [3, 4], photoluminescence layers [5], carbon nitride nano-tubes [6, 7], biosensor [8] and anti-biomaterials [9, 10], ultra low dielectric constant material [11] or variable band gap properties [12]. Hypothetical prediction regarding the mechanical properties of $\beta-C_{3} N_{4}$ solid to those of diamond [13] has attracted a great interest towards carbon-nitrogen materials. Until now there is no conclusive evidence about the possibility of synthesizing such super hard crystalline solids. Major significant obstacles to the synthesis of crystalline $\beta-C_{3} N_{4}$ are 1) the incorporation of the nitrogen in the carbon layer to reach a N/C ratio of $\approx 1.33$ and 2) the existence of $\mathrm{N}-\mathrm{H}$ and $\mathrm{C}-\mathrm{H}_{\mathrm{x}}$ bonds which are formed in most of the deposition systems. The graphitic carbon nitride polymers also possess a stacked two-dimensional structure, which could be regarded as $N$-substituted graphite in a

"Department of Physics, IIEST, Shibpur, Howrah-3, W.B., India; Tel: +913326684561; Fax: +913326682916;

E-mail: majuabhijit@gmail.com regular manner as mentioned by Zhang et al. [14]. Most of the published research work on a-CN $\mathrm{C}$ or $\mathrm{a}-\mathrm{HCN}_{\mathrm{x}}$ is based on $\mathrm{dc}$ and if magnetron sputtering [15, 16], pulsed laser deposition [17], ion beam deposition [18], PECVD [19], cathodic arc deposition [20], DBD [9-12, 21-24], etc. Schmidt et al. reported the influence of inert gases on the sputter process of carbon-nitride (CNx) thin films by HiPIMS. They reported that the deposition of $\mathrm{CNx}$ species is higher in case of $14 \% \mathrm{~N}_{2}$ in $\mathrm{Ar}$ inert gas medium compare to $\mathrm{Ne}$ or $\mathrm{Kr}$. Furthermore, it is mentioned that the $\mathrm{CN}^{+}$flux rises constantly with the $\mathrm{N}_{2}$ content $[25,26]$. Liau et al. studied the influence of atomic mixing on profiling of metal-semiconductor interfaces which depicts the penetration of one Ar ion into a sample during the sputtering process [27].

The main advantage of HiPIMS coatings include a denser coating morphology and higher hardness compared to conventional PVD coatings [28, 29, 30]. In plasma discharge volume, mostly atoms of buffer gas (Ar) are ionized, resulting in ion flux of about $0.1-1.0 \mathrm{~mA} / \mathrm{cm}^{2}$ towards the substrate which is hard to exceed in dc-MS. Further increase of discharge current leads to overheating of the magnets, melting of the target or the occurrence of arc when the target is covered by electrically insulating layer [30]. The ions in 
HiPIMS are more energetic than conventional dc-MS. HiPIMS exhibits higher energy $\mathrm{C}_{+}$ions compare to dc-MS discharge. Another factor is that the electron density measured in HiPIMS systems usually exceeds $10^{18} \mathrm{~m}^{-3}[30,31]$, which is about two-three orders of magnitude higher than in conventional dc-MS [2]. HiPIMS discharges produce ultrahigh dense plasma (plasma density is higher by two - three orders of magnitude than in dc magnetron discharges) with large fraction of carbon (graphite target) ionized species. Hence, the $\mathrm{C} / \mathrm{N}$ ion flux towards the substrate is large and leads to growth of smooth and dense films with higher adhesion. The plasma density during HiPIMS pulse is typically large, due to high applied power density, but their mean values, averaged over the whole period, are similar to those of with dc discharges [32-35]. The surface chemical property and chemical bonding states of a- $\mathrm{CN}_{\mathrm{x}}$ films are frequently analyzed by XPS. The chemical bonding states have been analyzed based on the peak fitting of $\mathrm{C} 1 \mathrm{~s}$ and $\mathrm{N} 1 \mathrm{~s}$ spectra $[1-3,13,14,21,24]$, and there have been several differing arguments regarding the fitting of these spectra. However, the interpretation of these data varies widely in the literature, since the different bonding configuration is mostly close in energy to each other. Moreover, the surface contamination, surface chemical bonding, surface charging due to nitrogen incorporation of those film is a big concern.

In this paper we discuss the bond structure and chemical transformations of amorphous carbon nitride film (deposited by HiPIMS and dc-MS) as a function of etching time (1 to 80 minutes).

\section{EXPERIMENT}

\section{1. a-CN $\mathrm{CN}_{\mathrm{x}}$ Films Prepared by dc-MS and HiPIMS}

a-CNx films were deposited in DC/HiPIMS magnetron sputtering system under different partial pressures (in this case at $5 \mathrm{~Pa}$ ) of $\mathrm{Ar} / \mathrm{N}_{2}$ buffer gas mixture, that was attached to a high vacuum chamber (base pressure $\sim 1 \times 10^{-6} \mathrm{mbar}$ ). The carbon target of diameter $50 \mathrm{~mm}$ with thickness $6 \mathrm{~mm}$ is connected to the magnetron sputtering gun (magnetron SW50 by Gencoa Ltd.). Thin films prepared by two different sputtering methods (i) conventional dc magnetron sputtering (dc-MS) [34] and (ii) High Power Impulse Magnetron Sputtering (HiPIMS) are compared in this paper. The discharge was always operated with a constant (average) current $0.3 \mathrm{~A}$; the magnetron was powered by a supply, Pinnacle 3000 (Advanced Energy) [35, 36]. The HiPIMS discharge was operated in a pulse regime with low repetition frequency of $100 \mathrm{~Hz}$ and the pulse width $100 \mu \mathrm{s}$. In this way the peak discharge current in HiPIMS configuration reached up to $35 \mathrm{~A}$ while averaged current $0.3 \mathrm{~A}$ was held always. Hence, we can expect that some fraction of sputtered C atoms is ionized due to high peak discharge current [35]. The HiPIMS discharge was ignited using home-build electronic power switch combined with dc supply, Pinnacle 3000; the system is described elsewhere e.g. [37, 49]. The a- $\mathrm{CN}_{\mathrm{x}}$ film is deposited on p-type $\mathrm{Si}(100)$ substrate and the duration of the deposition is $1 \mathrm{~h}$ for all the deposition.

\subsection{Ar Etching}

The deposited films were transported to another chamber (ex situ) and the films were etched by argon ion (99.999\% pure) with inbuilt etching gun (instruments-SPECS, model PU-IQE $12 / 38$ ). The executing pressure during etching is about $2 \times 10^{-6}$ mbar. The etching was performed at $2000 \mathrm{~V}$, emission current is $\sim 5 \mathrm{~mA}$ and ion current of $10 \mu \mathrm{A}$. The sample has been etched at different time duration (1 $\mathrm{min}$ to $80 \mathrm{~min}$ time span).

\subsection{Film Characterization}

The deposited films have been characterized by XPS. XPS measurements of a- $\mathrm{CN}_{\mathrm{x}}$ films were performed on a multitechnique $100 \mathrm{~mm}$ hemispherical electron analyser (VSW), using $\mathrm{Al} \mathrm{Ka}$ radiation (photon energy $1486.6 \mathrm{eV}$ ) as the excitation source and the binding energy (BE) of $A u\left(A u 4 \mathrm{f}_{7 / 2}\right.$ : $84.00 \mathrm{eV}$ ) as the reference. The XPS spectra were collected in a constant analyser energy mode, at a chamber pressure of $10^{-9} \mathrm{mbar}$ and pass energy of $23.5 \mathrm{eV}$ at $0.125 \mathrm{eV} / \mathrm{step}$ $[21,24,50]$. A clear image of the possible chemical bonds between nitrogen and carbon can be deduced from the peak fitting of the individual $\mathrm{C}-1 \mathrm{~s}, \mathrm{~N}-1 \mathrm{~s}$ and $\mathrm{O}-1 \mathrm{~s}$ lines into Lorentzian-Gaussian-shaped lines. The general strategy of the data evaluation was identical to those for standard spectroscopic techniques. The $\mathrm{C} 1 \mathrm{~s}, \mathrm{~N} 1 \mathrm{~s}$ peaks are broadened and also became asymmetric as the film is sputtered. The observed surface charging is caused by an anomalous surface charge distribution of the a- $\mathrm{CN}_{x}$ film. $\mathrm{Si}$ (2p) with a Binding Energy $(\mathrm{BE})=99.3 \mathrm{eV}$ was taken as a reference. The calibration details about this surface charging are discussed in our previous work [21, 24]. We used a-CN $\mathrm{N}_{\mathrm{x}}$ film (both HiPIMS and dc-MS), deposited on a Si substrate, of which a small part of the deposited film had been removed in order to get access to the Si surface. The binding energy of $\mathrm{C} 1 \mathrm{~s}$ is 284.5 , for N1s is $398.1 \mathrm{eV}$ and for O1s is $531.1 \mathrm{eV}$ taken as reference, and with respect to this value we have calculated the surface charging of $\mathrm{C} 1 \mathrm{~s}, \mathrm{~N} 1 \mathrm{~s}$ and $\mathrm{O} 1 \mathrm{~s}$ peak which have been obtained from experimental results [24,50]. The results shown below were corrected by subtracting the experimentally observed shift for all the analyses.

\section{RESULTS}

\subsection{XPS of a-CN $\mathrm{CN}_{\mathrm{x}}$ Film}

Figure 1 shows the survey scan (200 eV to $600 \mathrm{eV}$ ) of XPS spectra of a-CN $\mathrm{N}_{\mathrm{x}}$ film. It shows the $\mathrm{C} 1 \mathrm{~s}, \mathrm{~N} 1 \mathrm{~s}$ and $\mathrm{O} 1 \mathrm{~s}$ core level XPS spectra with different etching duration (from 1 minute to 80 minutes) for the films deposited by HiPIMS and dc-MS. There is drastic increase of carbon in the case of dcMS film compare to HiPIMS at longer etching duration. There are no shake up satellite peaks in the core level spectra and the peaks are asymmetric with medium FWHM (full width at half maximum) as shown in Figures 2, 3 and 4. A common 

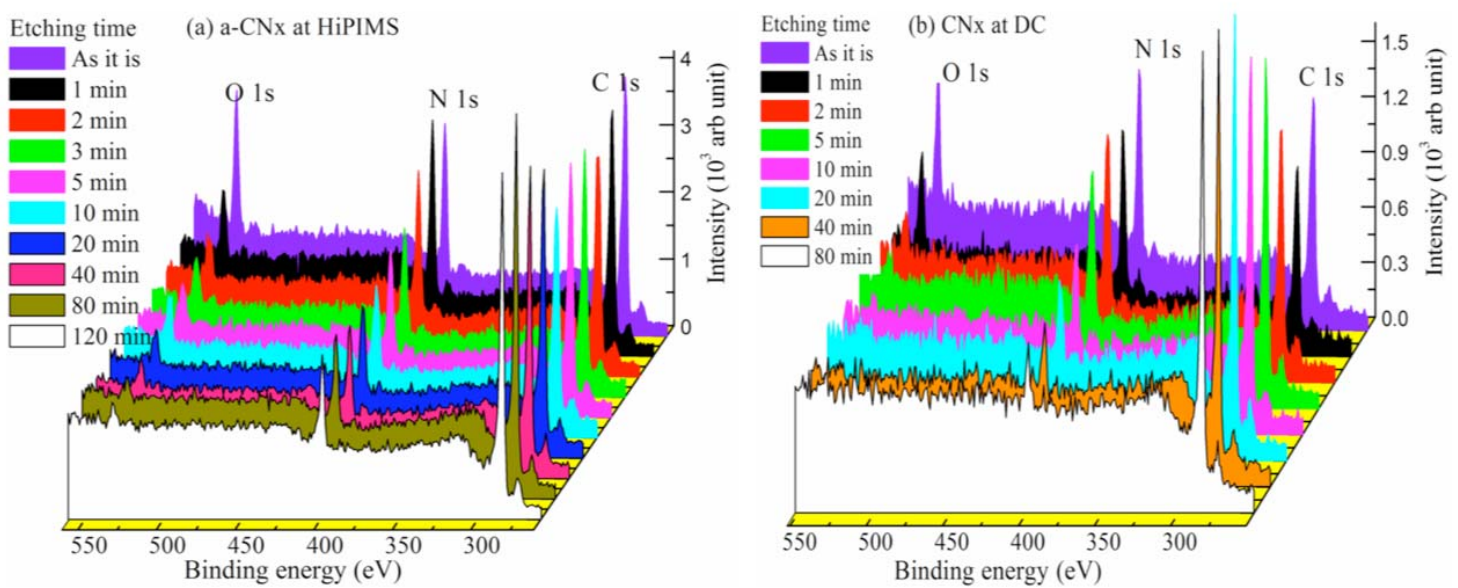

Figure 1: (Color online) Survey scan (200 eV to $600 \mathrm{eV}$ ) of XPS spectra of a-CN $\mathrm{CN}_{x}$ films deposited by (a) HiPIMS and (b) dc-MS. XPS spectra of a-CN $\mathrm{N}_{\mathrm{x}}$ are plotted as a function of sputtering duration. The film was etched by Ar gas up to 80 mins.
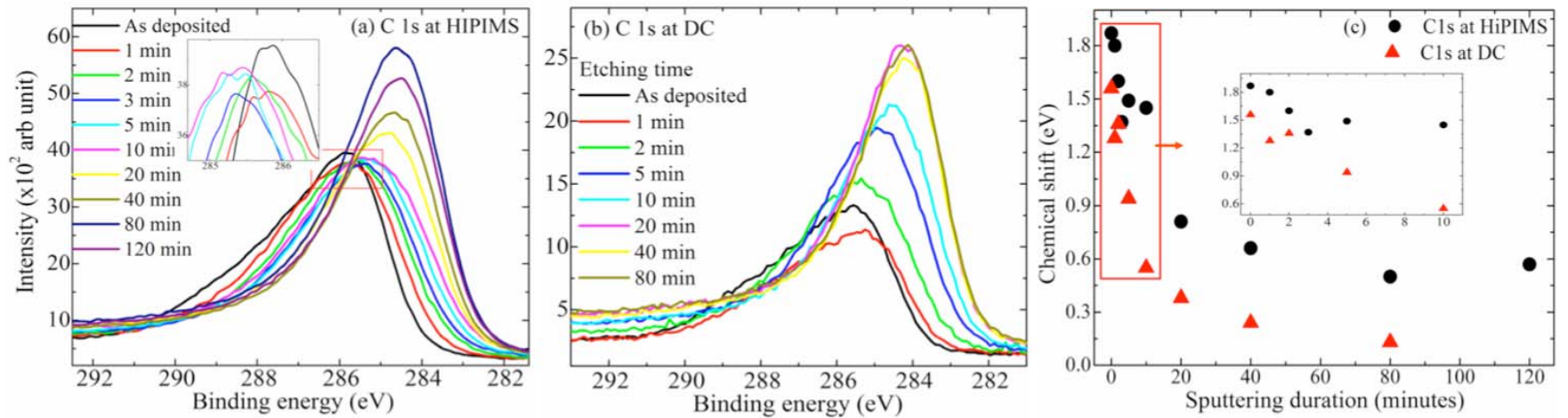

Figure 2: (Color online) XPS spectra of $\mathrm{C} 1 \mathrm{~s}$ peak of the a-CN $\mathrm{N}_{\mathrm{x}}$ film deposited by (a) HIPIMS, (b) dcMS. The C1s spectra plotted with respect to the duration of sputtering time. And (c) shows the surface charging of the corresponding $\mathrm{C} 1 \mathrm{~s}$ spectra as a function of sputtering time duration.
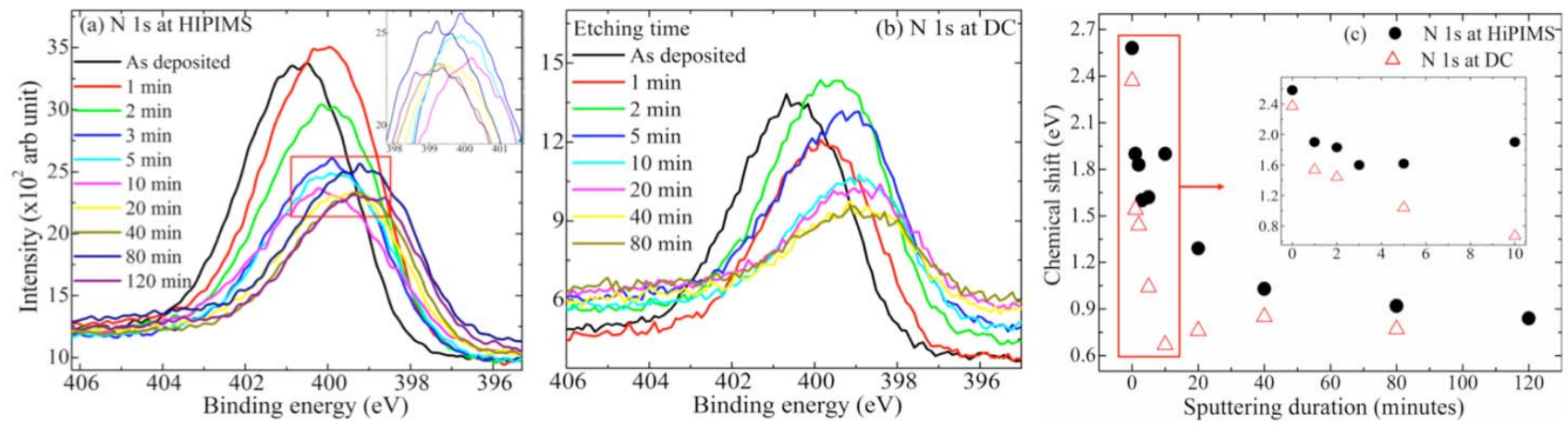

Figure 3: (Color online) XPS spectra of N1s peak of the a-CN $\mathrm{CN}_{\mathrm{x}}$ film deposited by (a) HIPIMS, (b) dcMS. The C1s spectra plotted with respect to the duration of sputtering time. And (c) shows the surface charging of the corresponding N1s spectra as a function of sputtering time duration.

feature is observed in both HiPIMS and dc-MS assisted deposited film that the oxygen and nitrogen is decreased as the etching duration is prolonged. The oxygen layer is persisting (11\%) in HiPIMS even at $120 \mathrm{~min}$ of etching whereas it is almost removed (only $2 \%$ ) at $80 \mathrm{~min}$ in the case of dc-MS film (Figure 5).

The $\mathrm{C} 1 \mathrm{~s}$ core peak is shifted gradually with longer duration of etching as shown in Figure $\mathbf{2 a}, \mathbf{b}$. It shows the XPS spectra of the HiPIMS and dc-MS films, sputtered at 1 to 120 min and 1 to $80 \mathrm{~min}$, respectively. The film deposited by HiPIMS shows higher values of surface charging (in binding energy) compare to the dc-MS film as shown in Figure 2c. The red (color) marked area (zoom insight) shows the etching duration is $1 \mathrm{~min}$ to $10 \mathrm{mins}$. Up to 10 minutes of etching, the dc-Ms film shows a drastic change in surface charging from $1.56 \mathrm{eV}$ to $0.55 \mathrm{eV}$ whereas it is $1.87 \mathrm{eV}$ to $1.45 \mathrm{eV}$ in the case of HiPIMS film. As the etching duration is prolonged 

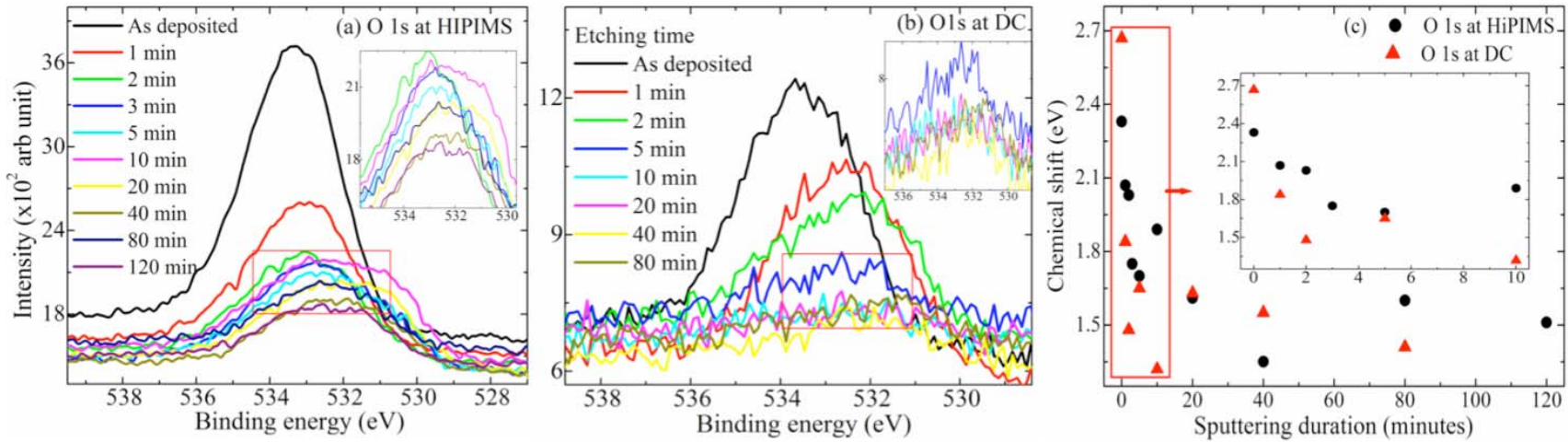

Figure 4: (Color online) XPS spectra of O1s peak of the a-CN $\mathrm{CN}_{\mathrm{x}}$ film deposited by (a) HIPIMS, (b) dcMS. The C1s spectra plotted with respect to the duration of sputtering time. And (c) shows the surface charging of the corresponding O1s spectra as a function of sputtering time duration.
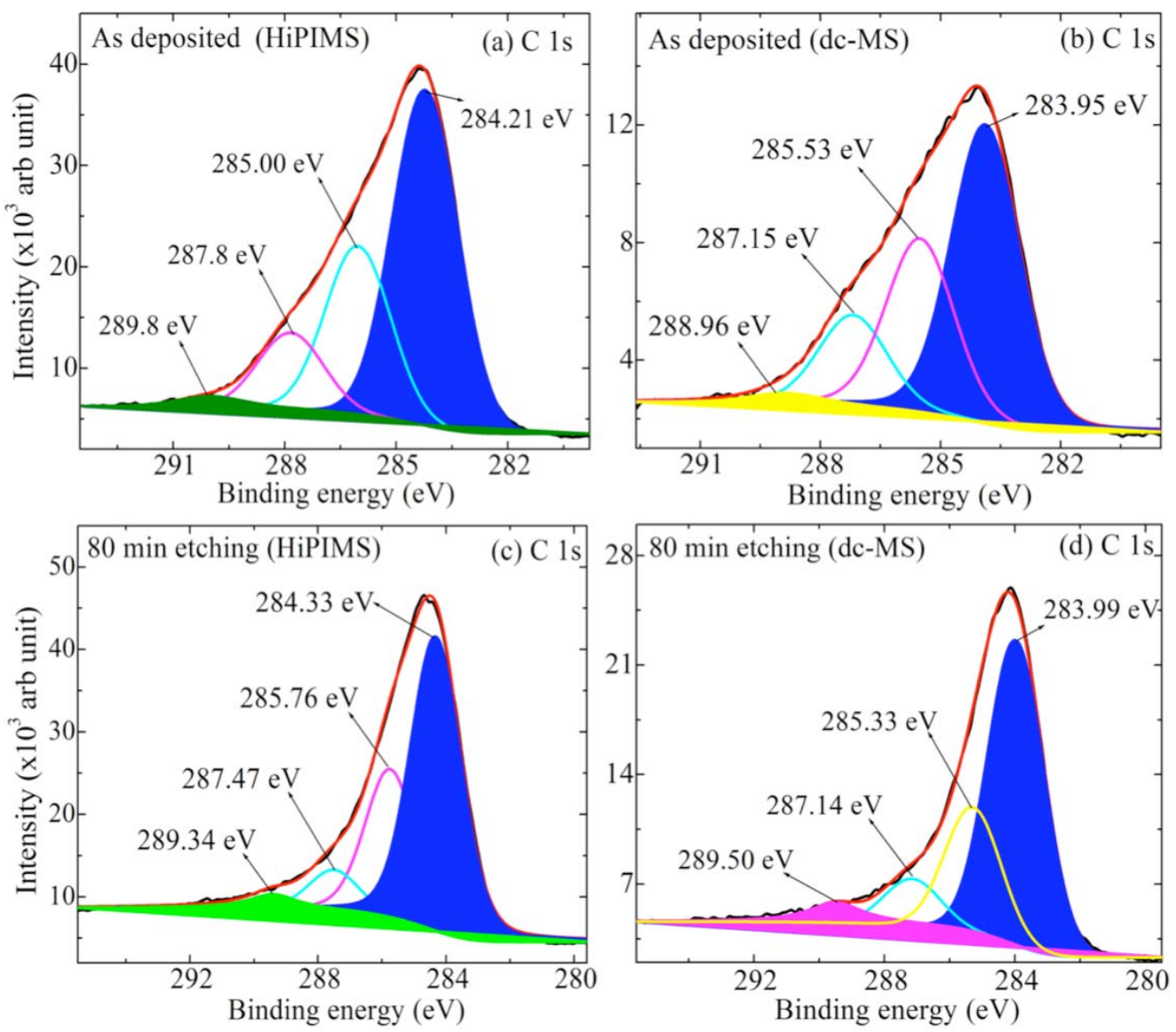

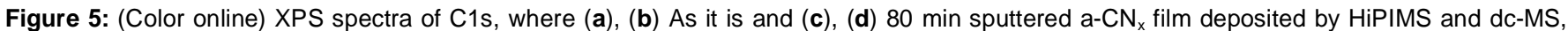
respectively. The un-etched film is referred as "As deposited". The data are presented after inelastic background subtraction and using Lorentzian-Gaussian fits. The intensity scales for the $\mathrm{C}$ spectra are not the same. The reference binding energy of $\mathrm{C} 1 \mathrm{~s}$ at $284.00 \mathrm{eV}$ and the core level components are representing the peak position of the fitted area.

from 10 to 80 minutes, the surface charging drop down from $1.45 \mathrm{eV}$ to $0.50 \mathrm{eV}$ and $0.55 \mathrm{eV}$ to $0.13 \mathrm{eV}$ in HiPIMS and dcMs films, respectively.

Figure $3 \mathbf{a}, \mathbf{b}$ show the shift of N1s core spectra of the films deposited by HiPIMS and dc-MS with prolonged Ar etching time ( $1 \mathrm{~min}$ to $80 \mathrm{~min}$ ). The film deposited by HiPIMS shows higher values of surface charging compare to the dc-MS as shown in Figure 3c. The red (color) marked area (zoom insight) shows the etching duration of 1 min to 10 mins. Up to 10 minutes of $\mathrm{Ar}$ ion etching, the dc-Ms film shows a drastic change in surface charging from $2.37 \mathrm{eV}$ to $0.67 \mathrm{eV}$ whereas it is $2.58 \mathrm{eV}$ to $1.91 \mathrm{eV}$ in the case of HiPIMS film. At 20 to 80 minutes of etching, the surface charging is almost constant in the case of dc-MS film whereas it is shifted from $1.29 \mathrm{eV}$ to $0.92 \mathrm{eV}$ for HiPIMS film. It is noticeable that at 10 mins to 20 
mins of etching the binding energy of HiPIMS film shifted from 1.92 to $1.29 \mathrm{eV}$ and on the other hand it is $0.67 \mathrm{eV}$ to $0.76 \mathrm{eV}$ for dc-MS film.

Figure $4 \mathbf{a}, \mathbf{b}$ shows the shift of O1s core spectra with prolonged etching time as similar to the C1s and N1s spectra. The red (color) marked area (zoom insight) shows that up to 10 minutes of etching, dc-Ms film shows a drastic fall in surface charging from 2.65 to $1.32 \mathrm{eV}$, whereas it is 2.3 to 1.7 $\mathrm{eV}$ for HiPIMS (Figure 4c). At longer etching duration (20 to $80 \mathrm{~min}$ ) the dc-MS film shows a gradual decrease in surface charging. On the other hand HiPIMS film shows a random behavior as it is decrease from $1.61 \mathrm{eV}(20 \mathrm{~min})$ to $1.35 \mathrm{eV}$ at $40 \mathrm{~min}$ and at $80 \mathrm{~min}$ it is increased to $1.6 \mathrm{eV}$; finally it is decreased to $1.51 \mathrm{eV}$ at $120 \mathrm{~min}$ of etching.

In Figure 5a and $\mathbf{b}, \mathrm{C} 1 \mathrm{~s}$ spectra of virgin a-CN $\mathrm{CN}_{\mathrm{x}}$ film deposited by HiPIMS and dc-MS exhibit four core level components in the range 283.95 to $284.21 \mathrm{eV}, 285.00$ to $285.53 \mathrm{eV}, 287.15$ to $287.8 \mathrm{eV}$ and 288.96 to $289.8 \mathrm{eV}$ which are assigned to $\mathrm{C}$ $\mathrm{C}, \mathrm{C}=\mathrm{N}, \mathrm{C} \equiv \mathrm{N}$ and $\mathrm{C}-\mathrm{O}$ bonds, respectively [21, 24, 49-61]. Similarly, C1s spectra of the 80 mins sputtered a-CN $\mathrm{CN}_{\mathrm{x}}$ film show four core level components in the range at 283.99 to $284.33 \mathrm{eV}, 285.33$ to $285.76 \mathrm{eV}, 287.14$ to $287.47 \mathrm{eV}$ and 289.34 to $289.50 \mathrm{eV}$ which are assigned to $\mathrm{C}-\mathrm{C}, \mathrm{C}=\mathrm{N}, \mathrm{C} \equiv \mathrm{N}$ and $\mathrm{C}-\mathrm{O}$ bonds. After 80 mins of Ar ion etching the fitted XPS spectra of $\mathrm{C} 1 \mathrm{~s}$ peak shows four core level components.

Figure $\mathbf{6 a}, \mathbf{b}$ and $\mathbf{c}$, d show the peak fitted XPS spectra of $\mathrm{N} 1 \mathrm{~s}$, un-sputtered and $80 \mathrm{~min}$ sputtered $\mathrm{a}-\mathrm{CN}_{\mathrm{x}}$ film. Here, Figure $(a, c)$ and $(b, d)$ are the N1s spectra of $a-C_{x}$ deposited by HiPIMS and dc-MS, respectively. The N1s spectrum of as it is film, (Figure 6), exhibits two core level components of core level spectra in the range (for HiPIMS and dc-MS) 398.17 to $398.47 \mathrm{eV}$ and 399.74 to $400.1 \mathrm{eV}$ are assigned to $\mathrm{N}-\mathrm{C}$, and $\mathrm{N}-\mathrm{O}$ bond, respectively [21, 24, 50, 51]. On the other hand 80 mins sputtered (c), (d) films exhibit three core level components in the range 398.66 to 398.75 $\mathrm{eV}, 400.40$ to $400.61 \mathrm{eV}$ and 403.50 to $404.02 \mathrm{eV}$ are assigned as $\mathrm{N} \equiv \mathrm{C}-, \mathrm{N}=\mathrm{C}$ - and $\mathrm{N}-\mathrm{O}$, respectively. We assign the peak at lower binding energy (397.88 to $398.5 \mathrm{eV}$ ) to nitrogen bonded to $\mathrm{sp}^{3}$ carbon and the peak at higher binding energy ( 398.6 to $399.80 \mathrm{eV}$ ) to nitrogen bonded to sp carbon [21, 24, 50-62]. The virgin "(a) and (b)" are plotted after the surface charging correction. On the other hand $80 \mathrm{~min}$ sputtered film is plotted without any shift correction.

Figure $7 \mathbf{a}, \mathbf{b}$ and $\mathbf{c}, \mathbf{d}$ show the peak fitted XPS spectra of O1s, un-sputtered and 80 min sputtered a- $\mathrm{CN}_{\mathrm{x}}$ film, whereas $(a, c)$ and $(b, d)$ are the O1s spectra of $a-C_{x}$ deposited by
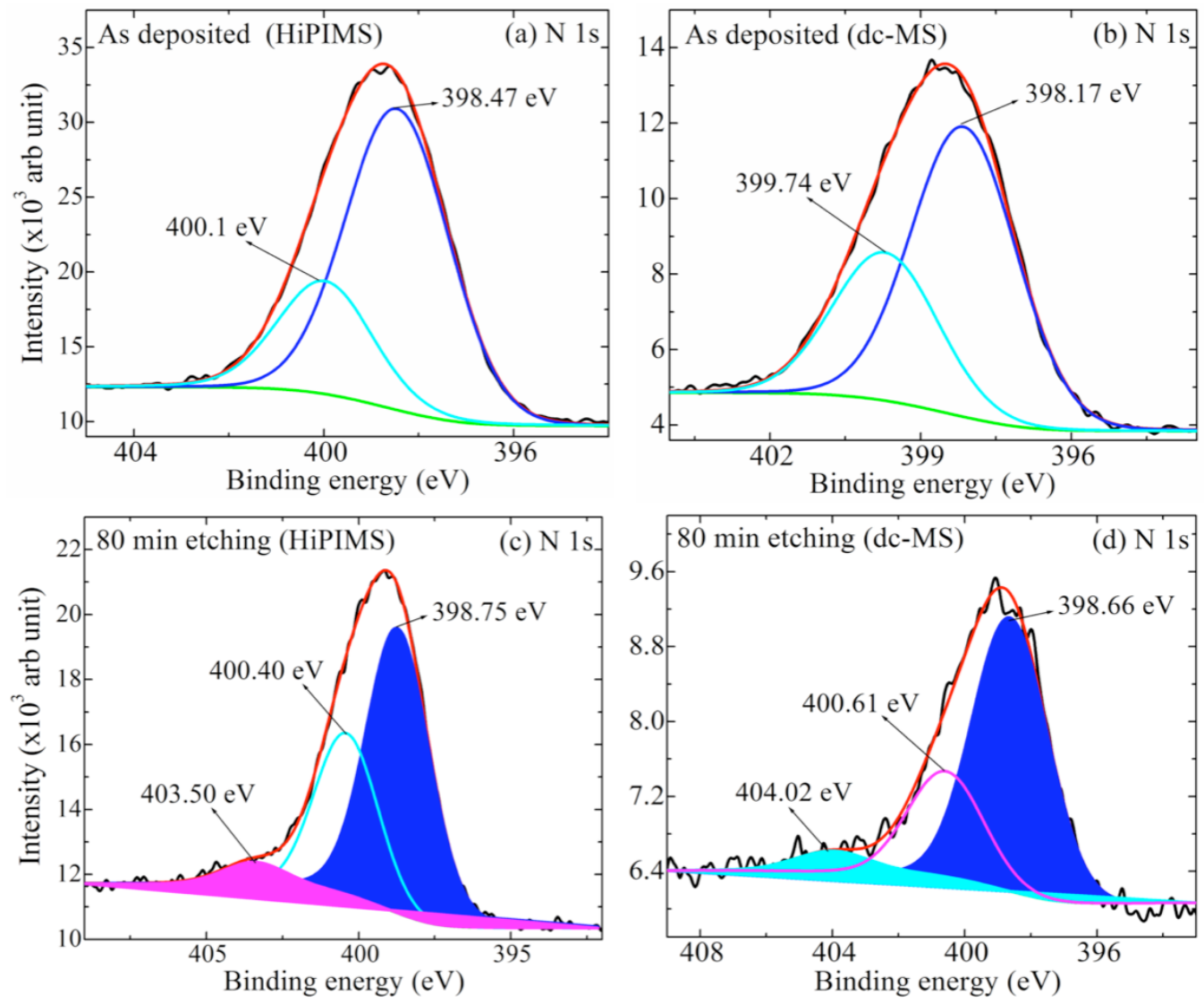

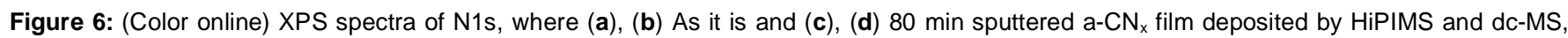
respectively. The un-sputtered film is referred as "As deposited". The data are presented after inelastic background subtraction and using Lorentzian-Gaussian fits. The intensity scales for the $\mathrm{N}$ spectra are not the same. The reference binding energy of $\mathrm{N} 1 \mathrm{~s}$ at $398.03 \mathrm{eV}$ and the core level components are representing the peak position of the fitted area. 

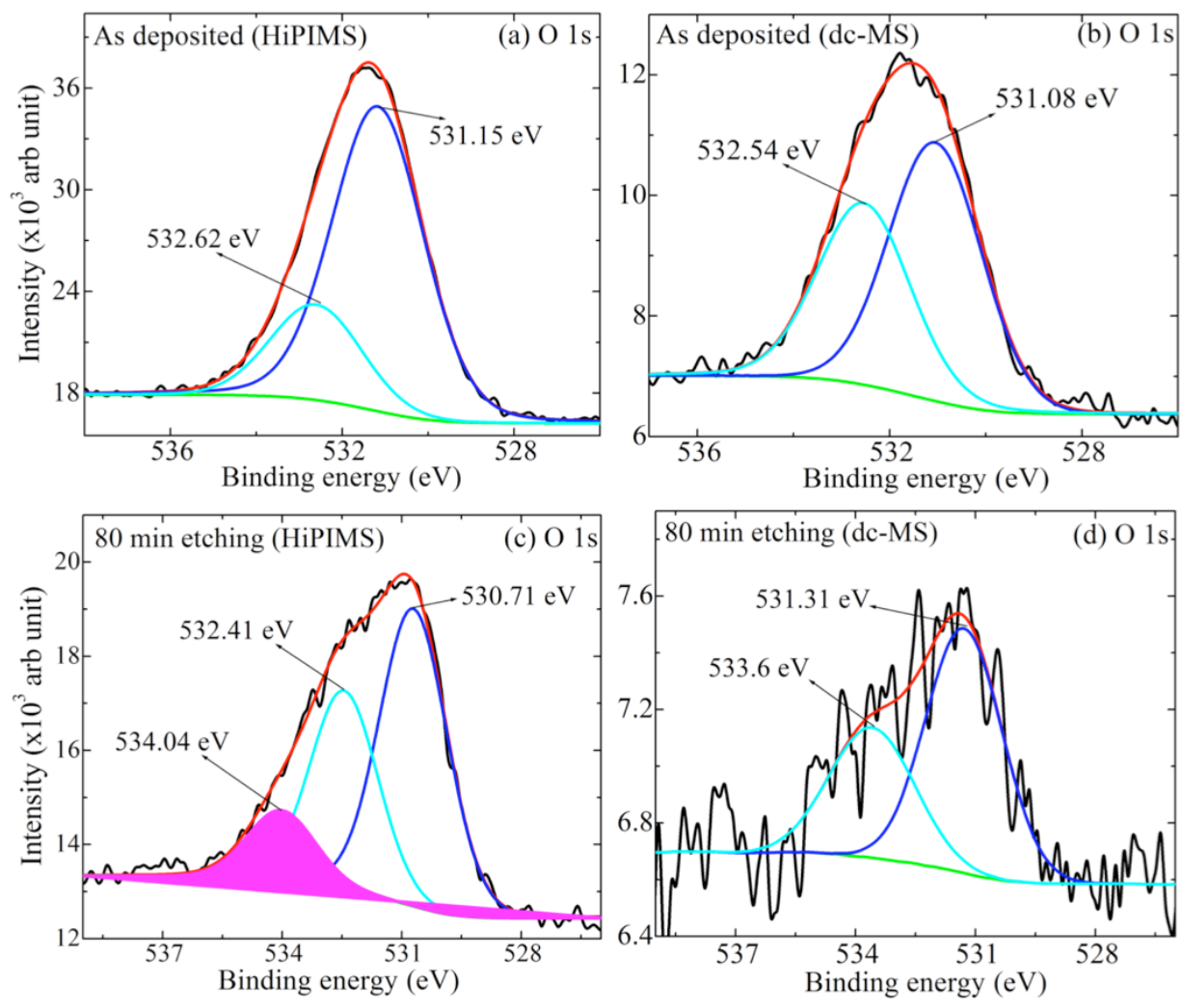

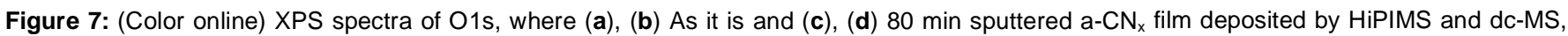
respectively. The un-sputtered film is referred as "As deposited". The data are presented after inelastic background subtraction and using Lorentzian-Gaussian fits. The intensity scales for the $\mathrm{O}$ spectra are not the same. The reference binding energy of $\mathrm{O} 1 \mathrm{~s}$ at $531.05 \mathrm{eV}$ and the core level components are representing the peak position of the fitted area.

HiPIMS and dc-MS, respectively. O1s spectra in Figures 7a, b show two core level components in the range 531.08 to $531.15 \mathrm{eV} \mathrm{eV}$ and 532.54 to $532.62 \mathrm{eV}$ assigned to adventitious (extrinsic or accidental) oxygen and surface oxygen and $\mathrm{C}-\mathrm{O}$ bonds, respectively [50, 61]. Figure 7c shows three core level components in O1s spectrum, that are $530.71 \mathrm{eV}, 532.41 \mathrm{eV}$ and $534.04 \mathrm{eV}$, are assigned as $\mathrm{N}-\mathrm{O}$, $\mathrm{C}-\mathrm{O}$ and $\mathrm{C}=\mathrm{O}$, respectively. Figure $\mathbf{7 d}$ shows two core level components in $\mathrm{O} 1 \mathrm{~s}$ spectrum at $531.31 \mathrm{eV}, 533.6 \mathrm{eV}$ are assigned as $\mathrm{N}-\mathrm{O}$ and $\mathrm{C}-\mathrm{O}$, respectively. The oxygen peaks give evidence on undesired absorptions or reactions of oxygen or moisture on the top of the film and formation of a surface layer of oxygen containing species. Even at $80 \mathrm{mins}$ of etching there is $6 \%$ oxygen is present in HiPIMS film due to the presence of $\mathrm{C}=\mathrm{O}$ bond in the film layer (Figures 4 and 9).

Figure 8a shows the FWHM of $\mathrm{C} 1 \mathrm{~s}, \mathrm{~N} 1 \mathrm{~s}$ and $\mathrm{O} 1 \mathrm{~s}$ of a-CN film. Figure $\mathbf{8 b}, \mathbf{c}$ depict the total amount of element (at\%) of $\mathrm{C}, \mathrm{N}$ and $\mathrm{O}$ of a-CN $\mathrm{C}$ as function of etching duration in HiPIMS and dc-MS, respectively.

\section{DISCUSSION}

Figure 5, shows the comparative study of core level spectra of $\mathrm{C} 1 \mathrm{~s}$ of un-sputtered and sputtered a-CN $\mathrm{CN}_{\mathrm{x}}$ film deposited by HiPIMS and dc-MS. One common feature for HiPIMS and dc-
MS as well as the virgin and sputtered film is that they exhibit four core level components in the peak fitted spectrum. The core level components of carbon (blue colour filled area) at the binding energy range $284.00-284.55 \mathrm{eV}$ is identified as originating from adventitious (extrinsic or accidental) carbon. Similarly, the C1s peak binding energy range at 288.5-289.8 $\mathrm{eV}$ is identified as originating from $\mathrm{CO}$ type bonds which are depending on the type of bonding such as ketones/aldehydes $(-\mathrm{CO} /-\mathrm{CHO})$ and carbonates $\left(-\mathrm{CO}_{3}\right)$. There is no shake up satellites peak in Figures 2-4 and 5-7, so $\mathrm{CO}$ type bond can only originate from $\mathrm{C}-\mathrm{O}$ and $\mathrm{C}=\mathrm{O}$ bond structure. Figure $\mathbf{5}$ shows that there are two $\mathrm{C} 1$ s peaks $\left(2^{\text {nd }}\right.$ and $\left.3^{\text {rd }}\right)$ in the range of 284.90 to $286.0 \mathrm{eV}$ and 286.50 -to $287.90 \mathrm{eV}$ which are assigned as substitutional $s p^{2} \mathrm{~N}$ in graphite like structures $(\mathrm{C}=\mathrm{N})$ and volatile phase like iso-nitrile $(-\mathrm{C} \equiv \mathrm{N})$, respectively [21, 24, 50-62].

Figure 8 shows the FWHM of core level peaks of virgin and 80 mins sputtered film deposited by HiPIMS and dc-MS. Noticeable interesting features are observed in $\mathrm{C} 1 \mathrm{~s}$ spectra: a) un-sputtered dc-MS films show higher FWHM $(4.17 \mathrm{eV})$ compare to the same of HiPIMS film $(3.65 \mathrm{eV})$. b) FWHM decreases at 80 mins of $\mathrm{Ar}$ ion sputtering of the film surface. The four $\mathrm{C} 1 \mathrm{~s}$ spectrums in Figure $\mathbf{5}$ shows a steep rise at lower binding energy and it decreases abruptly (or sudden drop) towards $286 \mathrm{eV}$ region with a broaden tail. At 80 mins of sputtering the FWHM is decreased from $3.65 \mathrm{eV}$ to $3 \mathrm{eV}$ in 

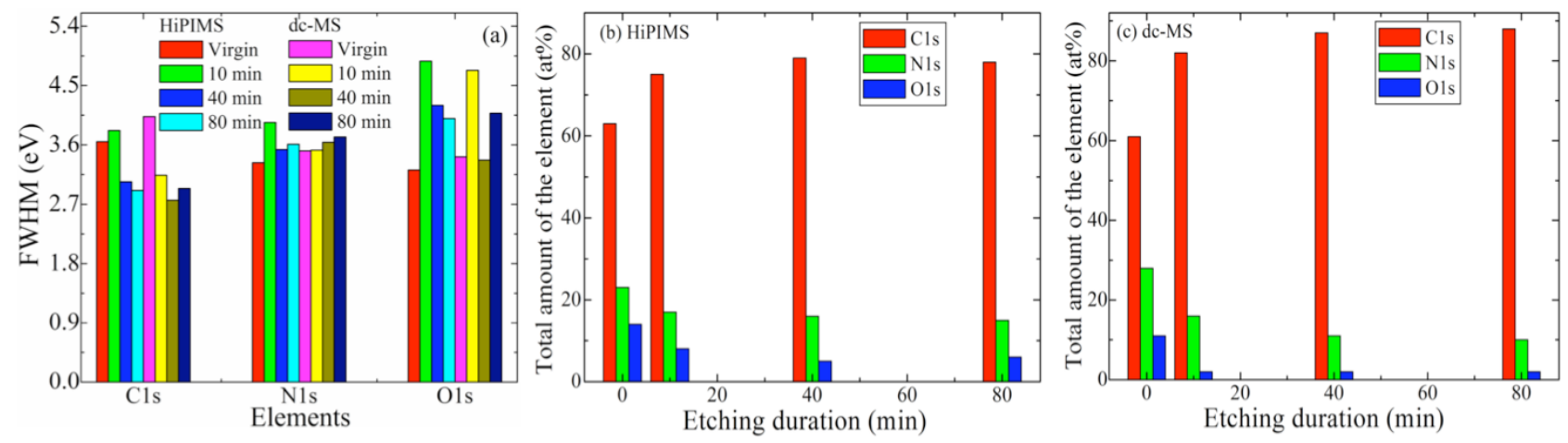

Figure 8: (Color online) (a) FWHM of C1s, N1s and O1s, and (b), (c) Relative intensity of C1s, N1s and O1s as a function of Ar-ion etching duration.

HiPIMS film whereas it is decreased from $4.17 \mathrm{eV}$ to $2.7 \mathrm{eV}$ in dc-MS film. It is interesting to observe that at 10 to 20 mins of sputtering the surface charging of HiPIMS film is about 0.7 $\mathrm{eV}$ whereas it is $0.09 \mathrm{eV}$ for dc-MS film. An anomalous change is observed at 5 mins to 10 mins of sputtering in the case of HiPIMS film whereas it shows the binding energy shift increase from $1.62 \mathrm{eV}$ to $1.90 \mathrm{eV}$. c) A shift of $1.5 \pm 0.7 \mathrm{eV}$ was noted which is considered as system calibration for virgin (as it is) films. As deposited films "(a) and (b)" are plotted with the surface charging correction. On the other hand 80 mins sputtered film is plotted without any shift correction. In HiPIMS film the $2^{\text {nd }}$ core level component of C1s at 285.00 $\mathrm{eV}$ appears at $285.76 \mathrm{eV}$ after 80 mins of $\mathrm{Ar}$ ion etching treatment whereas in dc-MS film, the $2^{\text {nd }}$ core level component of $\mathrm{C} 1 \mathrm{~s}$ peak remains in the same. It is observed in Figure 2-4, that the core level spectra moved to its virgin position due to etching. The higher surface charging is due to the presence of absorb oxygen layer at the top surface. The oxygen layer is removed gradually by the longer etching process and the core level peak is moved towards its virgin position. The reason behind the surface charging is explained in more details in our previous work [24]. d) The relative intensity of carbon in un-sputtered and sputtered HiPIMS films are about $63 \%$ and $78 \%$ respectively, whereas the ratios are $61 \%$ and $88 \%$ in dc-MS film (Figure $8 \mathbf{b}, \mathbf{c}$ ). e) The relative intensity of $\mathrm{C}-\mathrm{C}, \mathrm{C}-\mathrm{O}$ bond is increased and $\mathrm{C} \equiv \mathrm{N}$ is decreased in both HiPIMS and dc-MS film at 80 mins etching, respectively. On the other hand, the relative intensity of $\mathrm{C}=\mathrm{N}$ is increased in HiPIMS whereas it is decreased in dc-MS film (Figure 9).

Figure 6, shows the comparative study of un-sputtered and sputtered spectra of N1s of a-CN $\mathrm{N}_{\mathrm{x}}$ film deposited by HiPIMS and dc-MS. One common feature for HiPIMS and dc-MS film is that they show two core level components in virgin and three core level components in 80 mins sputtered film. Some noticeable features are observed in N1s spectra: a) unsputtered HiPIMS and dc-MS films show almost similar FWHM which are $3.3 \mathrm{eV}$ and $3.5 \mathrm{eV}$, respectively. b) FWHM at 80 mins of etching and it is $3.61 \mathrm{eV}$ and $3.72 \mathrm{eV}$ for HiPIMS and dc-MS film, respectively (Figure 9). Moreover, FWHM of N1s is increased by $\pm 0.15 \mathrm{eV}$ at 80 mins sputtered in both categories of films. Here we can notice that the peak FWHM of dc-MS film is relatively larger than HiPIMS in both sputtered and virgin films. The same phenomenon has been observed in the case of virgin $\mathrm{C} 1 \mathrm{~s}$ spectrum of a-CN $\mathrm{N}_{\mathrm{x}}$ film. c) One additional core level components is appeared in N1s spectrum in sputtered film (both in HiPIMS and dc-MS). The $2^{\text {nd }}$ and $3^{\text {rd }}$ core level components are in the range $400.40 \mathrm{eV}$ to $400.61 \mathrm{eV}$ and 403.50 to $404.02 \mathrm{eV}$ are assigned as $\mathrm{N}=\mathrm{C}$ and $\mathrm{N}-\mathrm{O}$. The $1^{\text {st }}$ core components (in the range of 398.66 to $398.75 \mathrm{eV}$ ) covered by blue color is assigned as N-C. Virgin film is plotted with shift correction $(1.5 \pm 0.4 \mathrm{eV})$ and the sputtered one is without shift correction. The $1^{\text {st }}$ core level
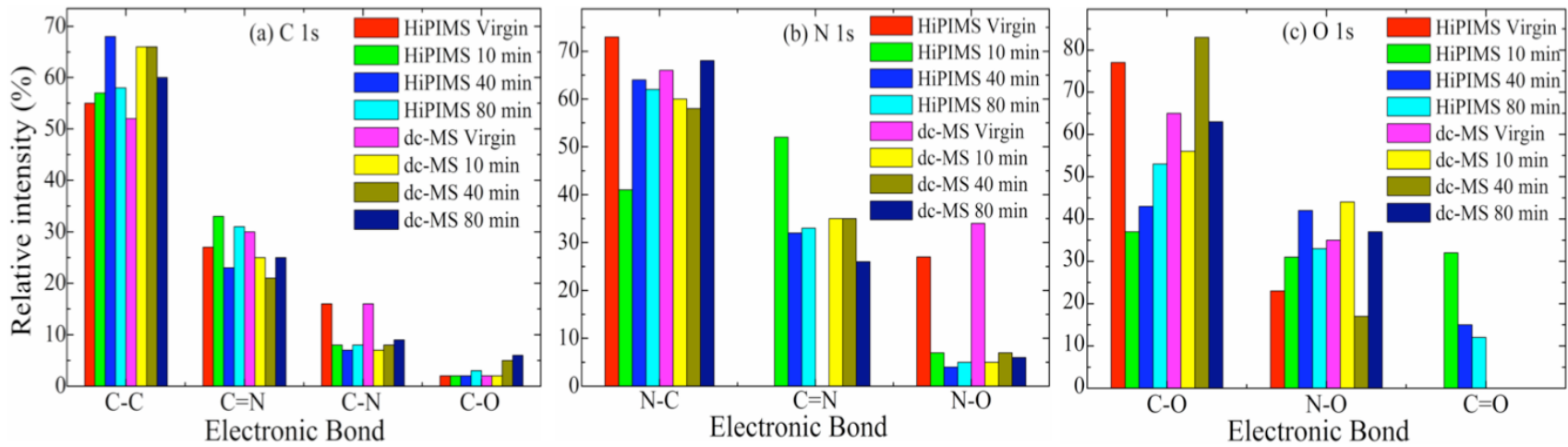

Figure 9: (Color online) Relative intensity of electronics bond in XPS spectra of (a) C1s, (b) N1s and (c) O1s as a function of Ar-ion etching duration. The un-etched film is referred as "Virgin". 
components of N1s spectra in sputtered film show $\pm 0.35 \mathrm{eV}$ shift compare to the same of virgin film. d) In sputtered film the relative intensity of $\mathrm{N}=\mathrm{C}$ bond is higher in HiPIMS (33\%) compare to the same of dc-MS (26\%). Relative intensity of N$\mathrm{C}$ bond decreases from $72 \%$ to $62 \%$, after etching treatment in HiPIMS whereas in dc-MS it is almost invariant. At 80 mins of etching the relative intensity of $\mathrm{N}-\mathrm{O}$ bond decreases drastically from $27 \%$ to $5 \%$ and $34 \%$ to $6 \%$ in HiPIMS and dc-MS, respectively. e) The relative intensity of nitrogen in un-sputtered and sputtered HiPIMS films are about $23 \%$ and $15 \%$ respectively, whereas they are $28 \%$ and $10 \%$ in the case of dc-MS film (Figure $\mathbf{8 b}, \mathbf{c}$ ).

Figure $\mathbf{7 a}, \mathbf{b}$ and $\mathbf{c}, \mathbf{d}$ show the comparative study of unsputtered and sputtered $\mathrm{O} 1 \mathrm{~s}$ spectra of a-CN $\mathrm{CN}_{\mathrm{x}}$ film deposited by HiPIMS and dc-MS, respectively. Here some noticeable features are observed in O1s spectra; a) it shows two core level components in un-sputtered film for both HiPIMS and dc-MS film. b) Interestingly at 80 mins sputtered HiPIMS film shows three core level components whereas there are two components in the case of dc-MS. Sputtered HiPIMS and dcMS films show almost similar FWHM which are $4.01 \mathrm{eV}$ and $4.08 \mathrm{eV}$, respectively. At 80 mins of etching the FWHM is decreased from 3.65 to $2.91 \mathrm{eV}$ in HiPIMS film whereas it is decreased from $4.03 \mathrm{eV}$ to $2.94 \mathrm{eV}$ in dc-MS film (Figure 9). The peak FWHM of dc-MS film is relatively larger than HiPIMS in both sputtered and virgin film. The same phenomenon has been observed in the case of virgin $\mathrm{C} 1 \mathrm{~s}$ spectrum of a-CN $\mathrm{N}_{x}$ film. c) O1s shows two core level components in virgin a-CN $\mathrm{CN}_{\mathrm{x}}$ film deposited by both the methods. These two core level components are assigned as $\mathrm{N}-\mathrm{O}$ and $\mathrm{C}-\mathrm{O}$. In Figure 7c, one additional core components is appeared at $534.04 \mathrm{eV}$ in $01 \mathrm{~s}$ spectrum is assigned as $\mathrm{C}=\mathrm{O}$ bond (80 mins sputtered HiPIMS). Two core components in O1s spectra is observed at 80 mins sputtered film assigned as $\mathrm{N}-\mathrm{O}$ and $\mathrm{C}-\mathrm{O}$ bond in dc-MS film.

d) Oxygen decrease from $11 \%$ to $2 \%$ after 80 mins etching treatment of dc-MS film whereas it is decreased from $14 \%$ to $6 \%$ in the case of HiPIMS film. The sputtered (at 80 mins) HiPIMS film shows higher residue of oxygen (6\%) compare to dc-MS film and it is in the form of double bond $(\mathrm{C}=\mathrm{O}$ at $534.04 \mathrm{eV}$ ). Figure 9 shows the relative intensity of $\mathrm{C}-\mathrm{C}$, $\mathrm{C}=\mathrm{N}, \mathrm{C}-\mathrm{N} / \mathrm{C} \equiv \mathrm{N}, \mathrm{C}-\mathrm{O}, \mathrm{N}-\mathrm{O}$ and $\mathrm{C}=\mathrm{O}$ bond obtain from peak fitted $\mathrm{C} 1 \mathrm{~s}, \mathrm{~N} 1 \mathrm{~s}$ and $\mathrm{O} 1 \mathrm{~s}$ spectra. The $\mathrm{C}$ and $\mathrm{N}$ bonds are mostly $\mathrm{sp}^{2}$ and $\mathrm{sp}^{3}$ type but oxygen dominated by conjugated double bond in HiPIMS film at C1s spectra. The spectra of $\mathrm{N} 1 \mathrm{~s}$ and $\mathrm{O} 1 \mathrm{~s}$ show two core level components in virgin a- $\mathrm{CN}_{\mathrm{x}}$ film deposited by both methods. These two core components are assigned as $\mathrm{N}-\mathrm{C}$ and $\mathrm{N}-\mathrm{O}$ in $\mathrm{N} 1 \mathrm{~s}$ spectra and $\mathrm{N}-\mathrm{O}$ and $\mathrm{C}-$ $\mathrm{O}$, respectively. At 80 mins of etching the films deposited dcMS and HiPIMS exhibits almost similar trend.

Oxygen formed single $(\mathrm{C}-\mathrm{O})$ and conjugated double $(\mathrm{C}=\mathrm{O})$ bond in HiPIMS film whereas it is only $\mathrm{C}-\mathrm{O}$ bond in dc-MS film. C-O and $\mathrm{C}=\mathrm{O}$ bonds strength are $358 \mathrm{~kJ} / \mathrm{mol}$ and 799 $\mathrm{kJ} / \mathrm{mol}$, respectively. We know that the higher bonding strength offers the lower stability due to more "s" character is involved in $\mathrm{sp}$ hybridization (where stability vary as $s p^{3}>s p^{2}>s p$ ). The hybrids are defined by the $p$ to $s$ ratio of the contributing orbital. For example, an $s p^{3}$ hybrid has $1 / 4(25 \%)$ of $s$ and $3 / 4(75 \%)$ of $p$. This fraction is called an $s$ (or $p$ ) character of the orbital. Thus, an $s p^{3}$ hybrid has $25 \% s$ character. Covalent bond ( $s p^{2}$ bond) is more stable bond than triple bond (sp). The relative intensity of $\mathrm{C}-\mathrm{O}, \mathrm{N}-\mathrm{O}$ bond is increased in HiPIMS at 80 mins etching.

The pulse operation provides new and additional parameters to control the deposition process that optimize the elemental composition in the deposited film. For these reasons HiPIMS is an attractive alternative which should be implemented in industrial coating processes. However, HiPIMS have still some disadvantages, such as lower deposition rate and higher cost of pulse power supplies. The carbon concentration of the up-sputtered film is almost same for both dc-MS and HiPIMS. The number of core level components obtained by peak fitting of $\mathrm{C} 1 \mathrm{~s}, \mathrm{~N} 1 \mathrm{~s}$ and $\mathrm{O} 1 \mathrm{~s}$ spectra of HiPIMS and dc-MS film shows more or less similar trend except some changes in $80 \mathrm{~min}$ sputtered film. On the other hand, the carbon concentration is higher in dc-MS compare to HiPIMS film at 80 mins of etching (Figure $\mathbf{8 b}$, c). Moreover, it is observed that the absorption of oxygen on the surface layer of the film is higher in HiPIMS compare to dc-MS film. There is $6 \%$ of oxygen in HiPIMS film whereas it is $2 \%$ in dc-MS film even the film is sputtered at 80 mins. It is interesting that the nitrogen concentration is lower at the top surface but it is higher in deeper layer of the HiPIMS films compare to the same of dc-MS film.

\section{CONCLUSION}

The spectroscopic analyses suggest that the presence of oxide layer is the major cause for the surface charging in the core peaks in a-CN $\mathrm{CN}_{\mathrm{x}}$ film deposited by HiPIMS and dc-MS. At longer duration of etching, the core electron peaks (C1s, N1s and O1s) in XPS show higher binding energy shift in HiPIMS compare to the film deposited by dc-MS plasma. The core peaks moved gradually toward its virgin position as the etching duration is prolonged from $1 \mathrm{~min}$ to $80 \mathrm{mins}$. The carbon concentration of the un-sputtered film is higher in dcMS compare to HiPIMS film at 80 mins of etching. Nitrogen incorporation in a- $\mathrm{CN}_{x}$ is higher in HiPIMS etching compare to dc-MS. The relative intensity of $C$ increased in both whereas $\mathrm{N}$ decreases faster (deep into the layer) in dc-MS film compare to HiPIMS at longer duration of etching. At 80 mins of sputtering there is $6 \%$ of oxygen in HiPIMS film due to majority of $s p^{2}$ bonding $(\mathrm{C}=0)$ whereas it is only $2 \%$ in dcMS. XPS spectra of un-sputtered dc-MS films show higher FWHM compare to the same of HiPIMS.

\section{ACKNOWLEDGEMENTS}

The work was supported by the Deutsche Forschungsgemeinschaft (DFG) through Sonderforschungsbereich SFB/TRR24. The author would like to thank to Mr. Steffen 
Drache, Institute for Physik, University of Greifswald, Germany, for the technical help during the experiment.

The authors like to thank Mr. Steffen Drache (Greifswald) for his assistance during the experiment.

\section{REFERENCE}

[1] Li D, Chung YW, Wong MS, Sproul WD. J Appl Phys 1993; 74: 219. http://dx.doi.org/10.1063/1.355304

[2] Yao H, Ching WY. Phys Rev B 1994; 50: 11231. http://dx.doi.org/10.1103/PhysRevB.50.11231

[3] Mansour A, Ugolini D. Phys Rev B 1993; 47: 10201. http://dx.doi.org/10.1103/PhysRevB.47.10201

[4] Robertson J. Thin Solid Films 2001; 383: 81 http://dx.doi.org/10.1016/S0040-6090(00)01786-7

[5] Zambov LM, Popov C, Abedinov N, Plass MF, Kulisch W, Gotszalk T. T Adv Mater 2000; 12: 656 . http://dx.doi.org/10.1002/(SICl)1521-4095(200005)12:9<656::AIDADMA656>3.0.CO;2-S

[6] Wang J, Miller DR, Gillan G. Chem Commun 2002; 19: 2258. http://dx.doi.org/10.1039/b207041c

[7] Plass MF, Popov C, Ivanov B, Mandl S, Jelinek M, Zambov LM. Appl Phys A 2001; 72: 21.

http://dx.doi.org/10.1007/s003390000687

[8] Lee SP. Sensors 2008; 8: 1508.

http://dx.doi.org/10.3390/s8031508

[9] Majumdar A, Schröder K, Hippler R. J Appl Phys 2008; 104: 074702. http://dx.doi.org/10.1063/1.2990054

[10] Majumdar A, Ummanni R, Schröder K, Walther R, Hippler R. J Appl Phys 2009; 106: 034702. http://dx.doi.org/10.1063/1.3190558

[11] Majumdar A, Das SC, Shripathi T, Hippler R. Chem Phys Lett 2012; 524: 62-67.

http://dx.doi.org/10.1016/i.cplett.2011.12.054

[12] Majumdar A, Bogdanowicz R, Mukherjee S, Hippler R. Thin Solid Films 2013; 527: 151.

http://dx.doi.org/10.1016/i.tsf.2012.11.020

[13] Liu AY, Cohen ML. Science 1989; 245: 841. http://dx.doi.org/10.1126/science.245.4920.841

[14] Zhang Y, Mori T, Ye J. Sci Adv Mater 2012; 4: 282 http://dx.doi.org/10.1166/sam.2012.1283

[15] Yu KM, Cohen ML, Haller EE, Hansen WL, Liu AY, Wu IC. Phys Rev B 1994; 49: 5034. http://dx.doi.org/10.1103/PhysRevB.49.5034

[16] Li Y, Zhang ZB, Xie SS, Yang GZ. Chem Phys Lett 1995; 247: 253. http://dx.doi.org/10.1016/0009-2614(95)01209-7

[17] Riedo E, Comin F, Chevrier J, Bonnot AM. J Appl Phys 2000; 88: 4365.

http://dx.doi.org/10.1063/1.1309041

[18] Ogata K, Chubaci JFD, Fujimoto F. J Appl Phys 1994; 76: 3791. http://dx.doi.org/10.1063/1.358497

[19] Freire FL, Franceschini DF. Thin Solid Films 1997; 293: 236 http://dx.doi.org/10.1016/S0040-6090(96)08979-1

[20] McCulloch DG, Merchant AR. Thin Solid Films 1996; 290: 99. http://dx.doi.org/10.1016/S0040-6090(96)09069-4

[21] Majumdar A, Schäfer J, Mishra P, Ghose D, Meichsner J, Hippler R. Surf Coat Technol 2007; 201: 6437. http://dx.doi.org/10.1016/i.surfcoat.2006.12.011

[22] Majumdar A, Scholz G, Hippler R. Surf Coat Technol 2009; 203: 2013.

http://dx.doi.org/10.1016/i.surfcoat.2009.01.038

[23] Majumdar A, Hippler R. Rev Sci Instrum 2007; 78: 75103. http://dx.doi.org/10.1063/1.2751408

[24] Majumdar A, Das G, Basvani KR, Heinicke J, Hippler R. J Phys Chem B 2009; 113: 15734 .

http://dx.doi.org/10.1021/ip906654m

[25] Schmidt S, Czigany Z, Greczynski G, Jensen J, Hultman L. J Vac Sci Technol A 2013; 31: 011503

http://dx.doi.org/10.1116/1.4769725
[26] Schmidt S., Czigany Z, Greczynski G, Jensen J, Hultman L. J Appl Phys 2012; 112: 013305. http://dx.doi.org/10.1063/1.4733692

[27] Liau ZL, Tsaur BY, Mayer JW. J Vac Sci Technol 1979; 18: 121 http://dx.doi.org/10.1116/1.569883

[28] Hippler R, Kersten $H$, Schmidt M, Schoenbach KH, Eds. Low Temperature Plasmas, Wiley-VCH: Wein-Heim 2008; Vol. 2.

[29] Ellmer K. In: Low Temperature Plasmas. Hippler R, Kersten $\mathrm{H}$, Schmidt M, Schoenbach KH, Eds. Wiley-VCH: Weinheim 2009; Vol. 2: p. 675.

[30] Chapman B. Glow Discharge Processes, Willey and Sons 1981.

[31] Bradley JW, Welzel T. J Phys D: Appl Phys 2009; 42: 093001.

[32] Helmersson U, Lattemann M, Bohlmark J, Ehiasarian AP, Gudmundsson JT. Thin Solid Films 2006; 513: 1.

http://dx.doi.org/10.1016/.tsf.2006.03.033

[33] Gudmundsson JT, Alami J, Helmersson U. Appl Phys Lett 2001; 78 : 3427.

http://dx.doi.org/10.1063/1.1376150

[34] Ellmer K. Magnetron Discharges for Thin Film Deposition; in: Low temperature plasma physics, Edds. Hippler R, Pfau S, Schmidt M, Schoenbach KH, Wiley-Vch 2008; 329.

[35] Gudmundsson JT, Brenning N, Lundin D, Helmersson U. J Vac Sci Technol 2012; A30(3): 030801

http://dx.doi.org/10.1116/1.3691832

[36] Sarakinos K, Alami J, Konstantinidis S. Surf Coat Technol 2010; 204 1661.

http://dx.doi.org/10.1016/i.surfcoat.2009.11.013

[37] Stranak V, Quaas M, Wulff H, Hubicka Z, Wrehde S, Tichy M, Hippler R. J Phys D: Appl Phys 2008; 41: 055202.

[38] Stranak V, Cada M, Hubicka Z, Tichy M, Hippler R. J Appl Phys 2010; 108: 043305. http://dx.doi.org/10.1063/1.3467001

[39] Stranak V, Drache S, Cada M, Hubicka Z, Tichy M, Hippler R. Contrib Plasma Phys 2011; 51(2-3): 237. http://dx.doi.org/10.1002/ctpp.201000065

[40] Stranak V, Wulf H, Bogdanowicz R, Drache S, Hubicka Z, Cada M, Tichy M, Hippler R. Eur Phys J D: Appl Phys 2011; 64: 427.

[41] Stranak V, Wulff H, Rebl H, Zietz C, Arndt K, Bogdanowicz R, Nebe B, Bader R, Podbielski A, Hubicka Z, Hippler R. Mat Sci Eng C 2011; 31: 1512.

http://dx.doi.org/10.1016/i.msec.2011.06.009

[42] Hoene A, Patrzyk M, Walschus U, Stranak V, Hippler R, Testrich H, Meichsner J, Juergen, Finke B, Rebl H, Nebe B, Zietz C, Bader R, Rainer, Podbielski A, Schlosser M. J Mater Sci - Mater Med 2013; 24: 761.

http://dx.doi.org/10.1007/s10856-012-4839-4

[43] Konstantinidis S, Ricard A, Ganciu M, et al. J Appl Phys 2004; 95: 2900.

http://dx.doi.org/10.1063/1.1646452

[44] Kouznetsov V, Macak K, Schneider JM, Helmersson U, Petrov I. Surf Coat Technol 2006; 122: 293.

[45] Gudmundsson JT, Alami J, Helmersson U. Appl Phys Lett 2001; 78: 3427.

http://dx.doi.org/10.1063/1.1376150

[46] Helmersson U, Lattemann M, Bohlmark J, Ehiasarian AP, Gudmundsson JT. Thin Solid Films 2006; 513: 1.

http://dx.doi.org/10.1016/.tsf.2006.03.033

[47] Vethuska A, Ehiasarian AP. J Phys D: Appl Phys 2008; 41: 015204.

[48] Alami J, Sarakinos K, Uslu F, Klever C, Dukwen J, Wuttig M. J Phys D: Appl Phys 2009; 42: 115204.

[49] Ehiasarian AP, Munz WD, Hultman L, Helmersson U, Petrov I. Surf Coat Technol 2003; 267: 163.

[50] Majumdar A, Das SC, Shripathi T, Heinicke J, Hippler R. Surf Sci 2013; 609: 53.

http://dx.doi.org/10.1016/isusc.2012.11.003

[51] Moulder JF, et al. Handbook of X-ray Photoelectron Spectroscopy; Perkin-Elmer Corporation: Eden Prairie, Minnesota 1992.

[52] Ronning C, Feldermann H, Merk R, Hofsass H, Reinke P, Thiele JU. Phys Rev B 1998; 58: 2207. http://dx.doi.org/10.1103/PhysRevB.58.2207

[53] Zheng WT, Yu WX, Li HB, Wang YM, Cao PJ, Jin ZS, Broitman E, Sundgren JE. Diamond Relat Mater 2000; 9: 1790. http://dx.doi.org/10.1016/S0925-9635(00)00314-9 
[54] Rodil SE, Ferrari AC, Robertson J, Milne WI. J Appl Phys 2001; 89: 5425. http://dx.doi.org/10.1063/1.1365076

[55] Ohta R, Lee KH, Saito N, Inoue Y, Sugimura H, Takai O. Thin Solid Films 2003; 434: 296.

http://dx.doi.org/10.1016/S0040-6090(03)00457-7

[56] Souto S, Pickholz M, dos Santos MC, Alvarez F, Phys Rev B 1998; 57: 2536.

http://dx.doi.org/10.1103/PhysRevB.57.2536

[57] Boyd KJ, Marton D, Todorov SS, et al. J Vac Sci Technol 1995; A13: 2110.

http://dx.doi.org/10.1116/1.579528
[58] Bhattacharyya S, Cardinaud C, Turban G. J Appl Phys 1998; 83: 4491.

http://dx.doi.org/10.1063/1.367211

[59] Bhattacharyya S, Hong J, Turban G. J Appl Phys 1998; 83: 3917. http://dx.doi.org/10.1063/1.367312

[60] Lindberg BJ, Hamrin K, Johansson G, Gelius U, Fahlman A, Nordling C, Siegbahn K. Physica Scripta 1970; 1: 286.

http://dx.doi.org/10.1088/0031-8949/1/5-6/020

[61] Rodil SE, Muhl S. Diamond Relat Mater 2004; 13: 1521-1531. http://dx.doi.org/10.1016/i.diamond.2003.11.008

[62] Hamrin K, Johansson G, Fahlman A, Nordling C, Siegbahn K Lindberg BJ. Chem Phys Lett 1968; 1: 557.

http://dx.doi.org/10.1016/0009-2614(68)80020-X 